\title{
Erratum to the prognosis analysis of RFWD2 inhibiting the expression of ETV1 in colorectal cancer
}

\author{
Wei Huang ${ }^{1,2}$, Xiumei Tian ${ }^{3,4}$, Xiaoying Guan ${ }^{3,4}$ \\ ${ }^{1}$ Department of Pathology, The Affiliated Shunde Hospital of Guangzhou Medical University, Foshan, China; ${ }^{2}$ Department of Pathology, The \\ Second Affiliated Hospital of Guangzhou Medical University, Guangzhou, China; ${ }^{3}$ Key Laboratory of Oral Medicine, Guangzhou Institute of Oral \\ Disease, Affiliated Stomatology Hospital of Guangzhou Medical University, Guangzhou, China; ${ }^{4}$ Department of Biomedical Engineering, Basic \\ Medicine School, Guangzhou Medical University, Guangzhou, China \\ Correspondence to: Xiaoying Guan. Key Laboratory of Oral Medicine, Guangzhou Institute of Oral Disease, Affiliated Stomatology Hospital of \\ Guangzhou Medical University, Huangsha Avenue 39\#, Liwan District, Guangzhou 510500, China; Department of Biomedical Engineering, Basic \\ Medicine School, Guangzhou Medical University, Xinzao, Panyu District, Guangzhou 511436, China. Email: gxy2012@163.com.
}

doi: $10.21037 /$ tcr-2020-008

View this article at: http://dx.doi.org/10.21037/tcr-2020-008

Erratum to: Transl Cancer Res 2020;9:508-21

The prognosis analysis of RFWD2 inbibiting the expression of ETV1 in colorectal cancer

In the article that appeared on Page 508-521 Vol 9, No 2 (February 2020) Issue of the journal Translational Cancer Research (1), there is an error on the affiliation of Dr. Wei Huang. Dr. Huang had two affiliations when doing this research. Thus, the affiliation "Department of Pathology, The Second Affiliated Hospital of Guangzhou Medical University, Guangzhou 510260, China" should also be added to this article.

The authors regret the error and all the inconveniences caused.

Open Access Statement: This is an Open Access article distributed in accordance with the Creative Commons AttributionNonCommercial-NoDerivs 4.0 International License (CC BY-NC-ND 4.0), which permits the non-commercial replication and distribution of the article with the strict proviso that no changes or edits are made and the original work is properly cited (including links to both the formal publication through the relevant DOI and the license). See: https:// creativecommons.org/licenses/by-ncnd/4.0/

\section{References}

1. Huang W, Tian XM, Guan XY. The prognosis analysis of RFWD2 inhibiting the expression of ETV1 in colorectal cancer. Transl Cancer Res 2020;9:508-21.

Cite this article as: Huang W, Tian X, Guan X. Erratum to the prognosis analysis of RFWD2 inhibiting the expression of ETV1 in colorectal cancer. Transl Cancer Res 2020;9(12):7809. doi: $10.21037 /$ tcr-2020-008 